\title{
The epidemiology of gastrointestinal stromal tumors in Taiwan, 1998-2008: a nation-wide cancer registry-based study
}

\author{
Nai-Jung Chiang ${ }^{1,2}$, Li-Tzong Chen ${ }^{1,2,3,4^{*}}$, Chia-Rung Tsai ${ }^{1}$ and Jeffrey S Chang ${ }^{1 *}$
}

\begin{abstract}
Background: To investigate the incidence of gastrointestinal stromal tumors (GISTs) in Taiwan and the impact of imatinib on the overall survival (OS) of GIST patients.

Methods: GISTs were identified from the Taiwan Cancer Registry (TCR) from 1998 to 2008. The age-adjusted incidence rates and the observed OS rates were calculated. Cox proportional hazards models were applied to examine the mortality risk in three time periods (1998-2001, 2002-2004, 2005-2008) according to the application and availability of imatinib.

Results: From 1998 to 2008, 2,986 GISTs were diagnosed in Taiwan. The incidence increased from 1.13 per 100,000 in 1998 to 1.97 per 100,000 in 2008. The most common sites were stomach (47-59\%), small intestine (31-38\%), and colon/rectum (6-9\%). The 5 -year observed OS was $66.5 \%$ (60.3\% for men, $74.2 \%$ for women, $P<.0001)$. GISTs in the stomach had a better 5-year observed OS (69.4\%) than those in the small intestine $(65.1 \%)(P<.0001)$. The outcome of GIST improved significantly after the more widespread use of imatinib; the 5-year observed OS increased from 58.9\% during 1998-2001 to 70.2\% during 2005-2008 ( $P$ <.0001). Younger age, female sex, stomach location, and later diagnostic years were independent predictors of a better survival.

Conclusions: The incidence of GIST has been increasing in Taiwan, partially due to the advancement of diagnostic technology/method and the increased awareness by physicians. The outcome of GIST has improved significantly with the availability and the wider use of imatinib.
\end{abstract}

Keywords: Gastrointestinal stromal tumors, Incidence, Imatinib, Survival

\section{Background}

Gastrointestinal stromal tumors (GISTs) are the most common mesenchymal neoplasms of the gastrointestinal system, characterized by an unique histological morphology and the expression of the KIT protein [1]. Previously, the majority of GISTs were diagnosed as smooth muscle tumors (e.g. leiomyoma and leiomyosarcoma) or as tumors of the nerve sheath origin (e.g. schwannoma and malignant nerve sheath tumors) [2,3]. Because GISTs were previously difficult to define due to the lack of specific markers, few epidemiologic studies were

\footnotetext{
*Correspondence: leochen@nhri.org.tw; jeffreychang@nhri.org.tw

${ }^{1}$ National Institute of Cancer Research, National Health Research Institutes,

2 F, No. 367, Sheng Li Road, Tainan 70456, Taiwan

${ }^{2}$ Division of Hematology/Oncology, Department of Internal Medicine,

National Cheng Kung University Hospital, 138 Sheng Li Road, Tainan 70456,

TaiwanFull list of author information is available at the end of the article
}

published with no nation-wide cancer registry-based study of GISTs from Asia [4,5]. The advancement of immunohistochemistry, molecular technology and the identification of KIT oncogene mutation in more than $80 \%$ of GISTs have accelerated our understanding of GISTs [6-8]. In Taiwan, the diagnosis of GISTs by CD117 or KIT staining was established and widely adopted since 2002. Prior to 2002, the diagnosis of GISTs was based on histology and other immunohistochemical markers (CD34, vimentin, keratin, smooth muscle actin (SMA), and S100) $[4,9]$. Using the Taiwan Cancer Registry (TCR) data from 1998 to 2008, our analysis elucidated the incidence and the distribution of GISTs before and after the implementation of CD117 or KIT staining for the definitive diagnosis of GISTs and compared them to those in the Western countries. 
Complete surgical resection remains the only curative treatment of primary localized GISTs. The 5-yr survival rate after complete surgical resection was $50 \%$ before the era of molecular targeted therapy $[10,11]$. The approval of imatinib mesylate (Gleevec ${ }^{\bullet}$ Novartis Pharma, Basel, Switzerland), an oral inhibitor of KIT and platelet-derived growth factor receptor, alpha polypeptide (PDGFRA), to treat metastatic GIST by the USA FDA in 2002 has markedly changed the outcomes and treatment options for GISTs [12]. In Taiwan, imatinib was approved for reimbursement by the National Health Insurance Administration since 2004. Our analysis assessed the survival of GISTs by three time periods: 1) 1998-2001, before the approval imatinib to treat GISTs; 2) 2002-2004, after the approval of imatinib to treat GISTs and before the coverage of imatinib by the National Health Insurance of Taiwan; and 3) 2005-2008, after the coverage of imatinib by the National Health Insurance of Taiwan.

\section{Methods}

\section{Data sources}

The GIST cases diagnosed from January 1, 1998 to December 31, 2008 were identified from the TCR established in 1979 to track the cancer incidence and mortality in Taiwan [13]. Hospitals with more than 50 beds in Taiwan are mandated to report confirmed cases of malignancy to the TCR, which captures $97 \%$ of the cancer cases in Taiwan [13]. The quality of a cancer registry is measured by the percentage of death certificate only cases (DCO\%) and the percentage of morphologically verified cases (MV\%), with a DCO\% of 0 and a MV\% of 100 representing a perfect data quality [14]. The quality of the TCR is comparable to the other well-established cancer registries in the world $[15,16]$ with a $\mathrm{DCO} \%$ of $1.2 \%$ and a MV\% of $89 \%$ [13].

\section{Study population}

Before 2002, the diagnosis of GISTs by CD117 or c-KIT staining was unavailable; therefore, for cases diagnosed from January 1, 1998 to December 31, 2001, the morphology $(\mathrm{M})$ codes of the International Classification of Disease for Oncology, Field Trial Edition (ICD-O-FT) were used to identify GIST cases with the algorithm established by Tran et al. [17], which included stromal sarcoma (8930), leiomyosarcoma (8890), epithelioid leiomyosarcoma (8891), cellular leiomyosarcoma (8892), bizarre leiomyosarcoma (8893), myxoid leiomyosarcoma (8896), smooth muscle cell tumor (8897), sarcoma not otherwise specified (8800), spindle cell sarcoma (8801), giant cell sarcoma (8802), small cell sarcoma (8803), epithelioid sarcoma (8804), mesenchymoma (8990), fibrosarcoma (8810), fibromyxosarcoma (8811), ganglioneuroma (9490), ganglioneuromatosis (9491), neurobalstoma (9500), neuroepithelioma (9503), ganglioglioma (9505), neurofibroma
(9504), schwannoma (9650), paragangmaluganglioma (8680), glomus tumor (8711), angiosarcoma (9120), and hemangiopericytoma (9150). The origin of tumors was limited to the following primary sites: esophagus, stomach, small intestine, colon and rectum. In addition, only those with confirmed malignant behavior by histological criteria (ICD-O-FT fifth digit of /3) were included.

GISTs diagnosed after January 1, 2002 were identified by the International classification of Diseases for Oncology, Third Edition (ICD-O-3) with the M code for gastrointestinal stromal sarcoma (8936). Only cases with confirmed malignant neoplasm (ICD-O-3 fifth digit of /3) were included.

\section{Statistical analysis}

The crude annual incidence was calculated by dividing the number of annual incident GIST cases by the annual population reported by the Directorate-General of Budget, Accounting, and Statistics of Taiwan (http://www.dgbas. gov.tw). The crude incidence rates were calculated for all GISTs combined, by sex, and by primary sites. All incidence rates (per 100,000) were age-adjusted to the 2000 U.S. standard population to generate the age-standardized incidence rates. The observed overall survival (OS) rates were calculated for all patients and by sex, primary sites, and diagnostic periods. Patients were followed from the date of diagnosis to death recorded in the national death database or to the end of follow-up on December 31, 2010. Cox proportional hazards models were performed to generate hazard ratios (HRs) and 95\% confidence intervals (CIs) for the risk of mortality associated with tumor site, sex, age, and the year of diagnosis. Stage at diagnosis (localized or metastatic), tumor size, and mitotic index were excluded from the analysis because of incomplete or lack of information. This study was approved by the Institutional Review Board of the National Health Research Institutes.

\section{Results}

\section{Characteristics of GIST patients}

During 1998-2008, 2,986 newly diagnosed GIST cases were recorded by the TCR. The age of GIST patients ranged from 18 to 96 years old. The median age was around $62-64$ years old and almost $75 \%$ of cases were diagnosed at $\geqq 50$ years of age (Table 1 ). For both sexes, the most common primary sites of GISTs were stomach (47-59\%), followed by small intestine (31-38\%), and colon/rectum (6-9\%).

A higher percentage of GIST originated from the small intestine was observed among those aged $<50$ years, and this percentage decreased with increasing age (from $43.8 \%$ among those younger than 50 years to $28.7 \%$ for those aged 70 years or older in 1998-2001; from $42.1 \%$ among those younger than 50 years to $31.4 \%$ for those 
Table 1 Characteristics of gastrointestinal stromal tumors patients by three time periods, Taiwan, 1998-2008

\begin{tabular}{|c|c|c|c|c|c|c|}
\hline \multirow{3}{*}{ Age, years } & \multicolumn{6}{|c|}{ Time period } \\
\hline & \multicolumn{2}{|c|}{$\begin{array}{c}1998-2001 \\
\mathrm{~N}=655\end{array}$} & \multicolumn{2}{|c|}{$\begin{array}{c}2002-2004 \\
N=846\end{array}$} & \multicolumn{2}{|c|}{$\begin{array}{c}2005-2008 \\
N=1485\end{array}$} \\
\hline & $\begin{array}{c}\text { Male } \\
\mathrm{N}=376\end{array}$ & $\begin{array}{l}\text { Female } \\
\mathrm{N}=\mathbf{2 7 9} \\
\end{array}$ & $\begin{array}{c}\text { Male } \\
\mathrm{N}=464\end{array}$ & $\begin{array}{l}\text { Female } \\
\mathrm{N}=382\end{array}$ & $\begin{array}{c}\text { Male } \\
\mathrm{N}=801\end{array}$ & $\begin{array}{l}\text { Female } \\
\mathrm{N}=684\end{array}$ \\
\hline$<50$ & $100(26.6 \%)$ & $78(28.0 \%)$ & $115(24.8 \%)$ & 86 (22.5\%) & 159 (19.9\%) & $129(18.9 \%)$ \\
\hline 50 to $<60$ & $70(18.6 \%)$ & $50(17.9 \%)$ & 89 (19.2\%) & 91 (23.8\%) & 191 (23.9\%) & $162(23.7 \%)$ \\
\hline 60 to $<70$ & $108(27.1 \%)$ & 74 (26.5\%) & $116(25 \%)$ & 96 (25.1\%) & $200(25.0 \%)$ & $184(26.9 \%)$ \\
\hline 70 to $<80$ & 78 (20.7\%) & $68(24.4 \%)$ & 118 (25.4\%) & $86(22.5 \%)$ & $182(22.7 \%)$ & 157 (23.0\%) \\
\hline$>80$ & $26(6.9 \%)$ & $9(3.2 \%)$ & $26(5.6 \%)$ & $23(6.0 \%)$ & $69(8.6 \%)$ & $52(7.6 \%)$ \\
\hline Median (min/max) & $62(26 / 87)$ & $62(23 / 88)$ & $63(19 / 89)$ & $62(18 / 91)$ & $64(19 / 96)$ & $64(22 / 94)$ \\
\hline \multicolumn{7}{|l|}{ Location } \\
\hline Stomach & 199 (52.9\%) & $164(58.8 \%)$ & 217 (46.8\%) & $196(51.3 \%)$ & 395 (49.3\%) & $375(54.8 \%)$ \\
\hline Small intestine & $143(38.0 \%)$ & 94 (33.7\%) & 177 (38.2\%) & $125(32.7 \%)$ & 289 (36.1\%) & $213(31.1 \%)$ \\
\hline Colon/rectum & $30(8.0 \%)$ & $20(7.2 \%)$ & $39(8.4 \%)$ & $34(8.9 \%)$ & $45(5.6 \%)$ & $43(6.3 \%)$ \\
\hline Esophagus/others $^{\mathrm{a}}$ & $4(1.1 \%)$ & $1(0.4 \%)$ & $31(6.7 \%)$ & 27 (7.1\%) & $72(9.0 \%)$ & $53(7.8 \%)$ \\
\hline
\end{tabular}

${ }^{a}$ Others: retroperitoneum and unspecific sites.

aged 70 years or older in 2002-2008 (Table 2). In contrast, the percentage of GIST originated from the stomach increased with age (from $48.3 \%$ among those younger than 50 years to $63.0 \%$ for those aged 70 years or older in $1998-$ 2001; from $42.9 \%$ among those younger than 50 years to $54.3 \%$ for those aged 70 years or older in 2002-2008). No significant trend was observed for the percentages of GISTs in colon/rectum or esophagus/others by increasing age.

\section{Incidence rates of GIST}

The age-standardized annual incidence rate increased from $1.13 / 100,000$ in 1998 , to $1.25 / 100,000$ in 2002 , and to $1.97 / 100,000$ in 2008 (Table 3 and Figure 1A). During

Table 2 Distribution of gastrointestinal stromal tumors by age groups and locations, Taiwan, 1998-2008

\begin{tabular}{|c|c|c|c|c|}
\hline \multirow{3}{*}{ Location } & \multicolumn{4}{|c|}{ 1998-2001 } \\
\hline & \multicolumn{4}{|c|}{ Age (years) } \\
\hline & $\begin{array}{c}<50 \\
N=178\end{array}$ & $\begin{array}{c}50 \text { to }<60 \\
N=120\end{array}$ & $\begin{array}{c}60 \text { to }<70 \\
N=176\end{array}$ & $\begin{array}{c}\geq 70 \\
N=181\end{array}$ \\
\hline Stomach & $86(48.3 \%)$ & $68(56.7 \%)$ & $95(54.0 \%)$ & $114(63.0 \%)$ \\
\hline Small intestine & $78(43.8 \%)$ & $41(43.8 \%)$ & $66(37.5 \%)$ & $52(28.7 \%)$ \\
\hline Colon/rectum & $12(6.7 \%)$ & $11(9.2 \%)$ & $15(8.5 \%)$ & $12(6.6 \%)$ \\
\hline \multirow[t]{2}{*}{ Esophagus/others $^{a}$} & $2(1.1 \%)$ & $0(0.0 \%)$ & $0(0.0 \%)$ & $3(1.7 \%)$ \\
\hline & \multicolumn{4}{|c|}{$2002-2008$} \\
\hline Location & $\begin{array}{c}<50 \\
N=489\end{array}$ & $\begin{array}{c}50 \text { to }<60 \\
N=533\end{array}$ & $\begin{array}{c}60 \text { to }<70 \\
N=596\end{array}$ & $\begin{array}{c}\geq 70 \\
N=713\end{array}$ \\
\hline Stomach & $210(42.9 \%)$ & $266(45.0 \%)$ & $320(53.7 \%)$ & $387(54.3 \%)$ \\
\hline Small intestine & $206(42.1 \%)$ & $182(34.2 \%)$ & $192(32.2 \%)$ & $224(31.4 \%)$ \\
\hline Colon/rectum & $36(7.4 \%)$ & $45(8.4 \%)$ & $40(6.7 \%)$ & $40(5.6 \%)$ \\
\hline Esophagus/others $^{a}$ & 37 (7.6\%) & $40(7.5 \%)$ & $44(7.4 \%)$ & $62(8.7 \%)$ \\
\hline
\end{tabular}

${ }^{\mathrm{a} O t h e r s: ~ r e t r o p e r i t o n e u m ~ a n d ~ u n s p e c i f i c ~ s i t e s . ~}$
2002-2008, men consistently had a slightly higher incidence rate of GIST than women (male to female ratio ranged from 1.02 to 1.26 ). The incidence rate increased gradually during 1998-2008, but more prominently after 2002. There was a rise in the incidence of GIST located in stomach, small intestine, and esophagus/others(retroperitoneum and unspecified sites), whereas the incidence of GIST in colon/rectum remained relatively stable (Table 3 and Figure 1B).

\section{Survival of GIST patients}

Overall, the 1-yr observed OS rate was $88 \%$ and the 5 -yr observed OS rate was $66.5 \%$ (Table 4 ). There was a significant sex difference in survival $(p<.0001)$ (Table 4$)$. For men, the 1 - and 5-yr observed OS rates were $86 \%$ and $60.3 \%$, respectively. For women, the 1 - and 5-yr observed OS rates were $90.6 \%$ and $74.2 \%$, respectively. Patients with GISTs from colon/rectum had the best prognosis with a 5 -yr observed OS rate of $72.4 \%$, followed by stomach (69.4\%), and small intestine (65.1\%) (Table 4). Women had a better prognosis than men for all sites. Among men, the 5 -yr observed OS rate was $66.6 \%, 62.1 \%$ and $60.7 \%$ for GIST in colon/rectum, stomach, and small intestine, respectively. For women, the 5-yr observed OS rate was $78.7 \%, 77.5 \%$ and $71.3 \%$ for GIST in colon/rectum, stomach, and small intestine, respectively. The 5-yr observed OS rate for all patients improved from 58.9\% during 1998-2001 to $67.0 \%$ during 2002-2004 and to $70.2 \%$ during 2005-2008 (Table 4 and Figure 2).

Age, sex, primary site, and the year of diagnosis independently predicted the mortality of GIST (Table 5). Patients older than 50 years had a 1.4 to 5.7 fold increase in the risk of death compared to those younger than 
Table 3 Age-standardized incidence (per 100,000) of gastrointestinal stromal tumors, Taiwan, 1998-2008 ${ }^{\mathrm{a}}$

\begin{tabular}{|c|c|c|c|c|c|c|c|}
\hline \multirow[t]{2}{*}{ Year } & \multirow[t]{2}{*}{ Total } & \multicolumn{2}{|c|}{ Gender } & \multicolumn{4}{|c|}{ Primary sites } \\
\hline & & Male & $\overline{\text { Female }}$ & Stomach & Small intestine & Colon/rectum & Esophagus/others $^{\mathbf{b}}$ \\
\hline 1998 & 1.13 & 1.03 & 1.24 & 0.53 & 0.31 & 0.11 & 0.01 \\
\hline 1999 & 1.20 & 1.17 & 1.22 & 0.56 & 0.37 & 0.08 & 0.01 \\
\hline 2000 & 1.14 & 1.06 & 1.22 & 0.53 & 0.32 & 0.07 & 0.02 \\
\hline 2001 & 1.05 & 1.04 & 1.07 & 0.52 & 0.30 & 0.04 & 0.00 \\
\hline 2002 & 1.25 & 1.26 & 1.23 & 0.66 & 0.40 & 0.11 & 0.09 \\
\hline 2003 & 1.55 & 1.72 & 1.39 & 0.74 & 0.57 & 0.13 & 0.11 \\
\hline 2004 & 1.59 & 1.79 & 1.38 & 0.79 & 0.58 & 0.11 & 0.10 \\
\hline 2005 & 1.64 & 1.81 & 1.46 & 0.9 & 0.52 & 0.10 & 0.12 \\
\hline 2006 & 1.70 & 1.77 & 1.63 & 0.88 & 0.57 & 0.12 & 0.12 \\
\hline 2007 & 1.75 & 1.91 & 1.59 & 0.91 & 0.60 & 0.09 & 0.15 \\
\hline 2008 & 1.97 & 2.20 & 1.75 & 1.00 & 0.65 & 0.12 & 0.20 \\
\hline
\end{tabular}

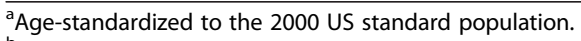

${ }^{b}$ Others: retroperitoneum and unspecific sites.

50 years old. Women had a better survival than men $(\mathrm{HR}=0.68,95 \% \mathrm{CI}: 0.60-0.77, P<0.0001)$. GISTs arising from the stomach had better prognosis than those from the small intestine regardless of the time periods, but this difference became non-statistically significant during

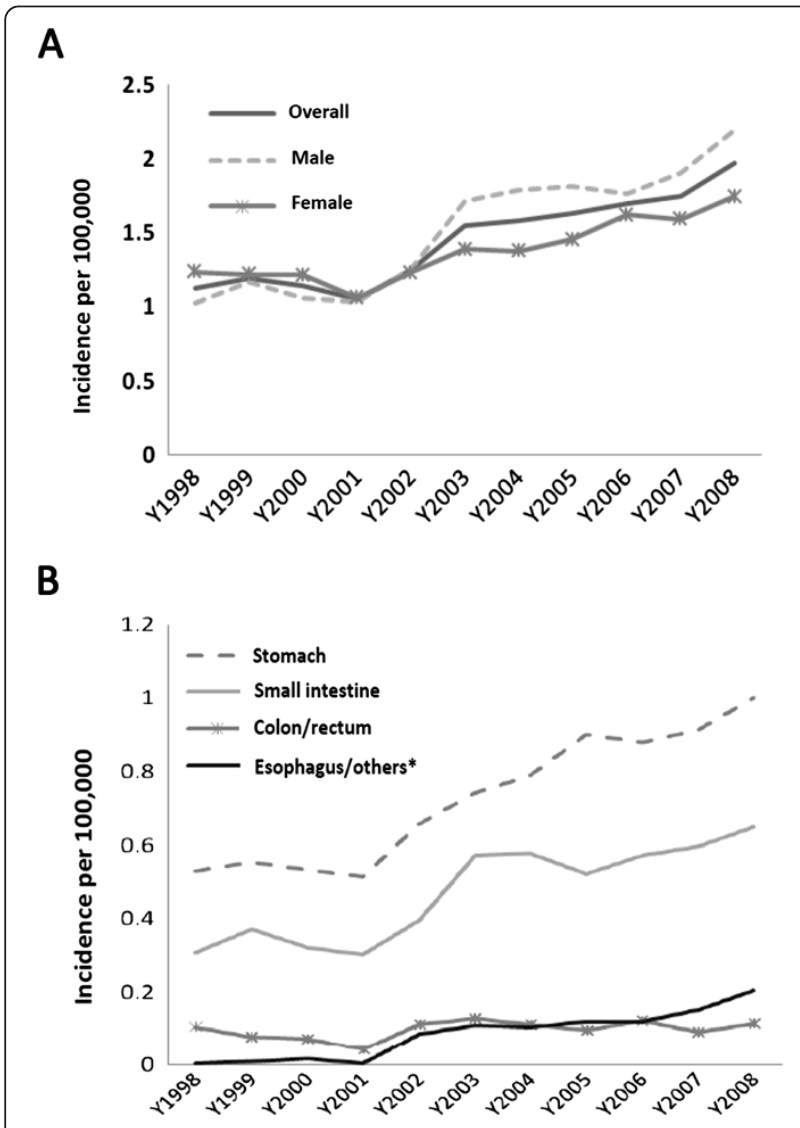

Figure 1 The incidence rate of gastrointestinal stromal tumors, Taiwan, 1998-2008: A) Overall and by sex; B) By primary sites.
2005-2008 ( $P=0.12$, Additional file 1: Table S1, S2, and S3). Compared with those diagnosed in 2005-2008, patients diagnosed in 1998-2001 ( $\mathrm{HR}=1.67,95 \% \mathrm{CI}: 1.42$ $1.97)$ and $2002-2004(\mathrm{HR}=1.25,95 \% \mathrm{CI}: 1.08-1.46)$ had a significantly higher risk of mortality (Table 5 ).

\section{Discussion}

Results of this first Asian nation-wide cancer registrybased study of GISTs showed that the annual incidence of GISTs in Taiwan ranged from 1 to 2 cases per 100,000. In a hospital-based retrospective cohort study, Tzen et al. estimated that the incidence of GIST in Taiwan during 1998-2004 was 1.37 cases per 100,000, which was similar to our result [18]. In a hospital-based retrospective cohort study, the annual incidence of GISTs in Hong Kong was estimated to be 1.68-1.96 per 100,000 [4]. In a study based on pathology reports from 38 hospitals, Cho et al. reported that the incidence of GISTs in Korea was approximately 1.6-2.2 per 100,000 [19]. Studies from Europe and North America reported a GIST incidence of 1.45 per 100,000 in Sweden [20], 0.65-0.90 per 100,000 in Spain [21], 0.6-1.9 per 100,000 in Norway [22], 0.66 in Italy [23], $0.85-1.00$ per 100,000 in France [24], 0.9 per 100,000 in Canada [25], 1.32 per 100,000 in United Kingdom [26], and 0.7 per 100,000 in USA [17]. Given the different study time periods and the lack of confirmation by KIT immunohistochemical staining in some studies, it is difficult to compare the incidence rates of GISTs across different countries; however, the published literature to date showed that the incidence rates of GISTs in different countries appeared to fall in a similar range.

Our analysis indicated that the incidence of GISTs in Taiwan increased during 1998-2008, with a more prominent rise since 2002 (Table 3 and Figure 1A). The possible reasons for the observed rise in the incidence of 
Table 4 One and 5-year observed overall survival rates of patients with gastrointestinal stromal tumors, Taiwan, 1998-2008

\begin{tabular}{|c|c|c|c|c|c|c|c|c|}
\hline \multirow{3}{*}{ Location } & \multicolumn{8}{|c|}{ 1998-2008 } \\
\hline & \multicolumn{4}{|c|}{ 1-year survival } & \multicolumn{4}{|c|}{ 5-year survival } \\
\hline & Overall & Male & Female & $P$ value $^{\mathrm{a}}$ & Overall & Male & Female & $P$ value $^{a}$ \\
\hline All sites & $88.0 \%$ & $86.0 \%$ & $90.6 \%$ & $<.0001$ & $66.5 \%$ & $60.3 \%$ & $74.2 \%$ & $<.0001$ \\
\hline Stomach & $90.1 \%$ & $87.7 \%$ & $92.8 \%$ & $<.0001$ & $69.4 \%$ & $62.1 \%$ & $77.5 \%$ & $<.0001$ \\
\hline Small intestine & $88.1 \%$ & $86.5 \%$ & $90.3 \%$ & 0.0009 & $65.1 \%$ & $60.7 \%$ & $71.3 \%$ & 0.0008 \\
\hline Colon/rectum & $87.7 \%$ & $89.5 \%$ & $85.6 \%$ & 0.1666 & $72.4 \%$ & $66.6 \%$ & $78.7 \%$ & 0.0732 \\
\hline \multirow[t]{2}{*}{ Esophagus/others ${ }^{b}$} & $71.3 \%$ & $66.4 \%$ & $77.8 \%$ & 0.1321 & $43.4 \%$ & $36.8 \%$ & $51.9 \%$ & 0.0897 \\
\hline & \multicolumn{8}{|c|}{$1998-2001$} \\
\hline All sites & $81.8 \%$ & $78.5 \%$ & $86.4 \%$ & $<.0001$ & $58.9 \%$ & $52.7 \%$ & $67.4 \%$ & $<.0001$ \\
\hline Stomach & $85.1 \%$ & $80.4 \%$ & $90.9 \%$ & 0.0010 & $61.4 \%$ & $53.3 \%$ & $71.3 \%$ & 0.0006 \\
\hline Small intestine & $77.6 \%$ & $75.5 \%$ & $80.9 \%$ & 0.0336 & $55.3 \%$ & $52.5 \%$ & $59.6 \%$ & 0.0368 \\
\hline Colon/rectum & $80 \%$ & $80 \%$ & $80 \%$ & 0.1118 & $60 \%$ & $50 \%$ & $75 \%$ & 0.0519 \\
\hline \multirow[t]{2}{*}{ Esophagus/others ${ }^{\mathrm{b}}$} & $60 \%$ & $75 \%$ & - & - & $40 \%$ & $50 \%$ & - & - \\
\hline & \multicolumn{8}{|c|}{$2002-2004$} \\
\hline All sites & $90.0 \%$ & $87.5 \%$ & $92.9 \%$ & $<.0001$ & $67.0 \%$ & $59.7 \%$ & $76.0 \%$ & $<.0001$ \\
\hline Stomach & $91.0 \%$ & $88.5 \%$ & $93.9 \%$ & $<.0001$ & $70.2 \%$ & $61.3 \%$ & $80.1 \%$ & $<.0001$ \\
\hline Small intestine & $90.4 \%$ & $89.3 \%$ & $92.0 \%$ & 0.4008 & $64.9 \%$ & $59.9 \%$ & $72.0 \%$ & 0.2272 \\
\hline Colon/rectum & $94.5 \%$ & $94.9 \%$ & $94.1 \%$ & 0.4290 & $80.8 \%$ & $74.4 \%$ & $88.2 \%$ & 0.3414 \\
\hline \multirow[t]{2}{*}{ Esophagus/others ${ }^{\mathrm{b}}$} & $74.1 \%$ & $61.3 \%$ & $88.9 \%$ & 0.0947 & $37.9 \%$ & $29.0 \%$ & $48.2 \%$ & 0.1277 \\
\hline & \multicolumn{8}{|c|}{$2005-2008$} \\
\hline All sites & $89.7 \%$ & $88.6 \%$ & $90.9 \%$ & $<.0001$ & $70.2 \%$ & $65.5 \%$ & $75.8 \%$ & $<.0001$ \\
\hline Stomach & $92.0 \%$ & $90.9 \%$ & $93.1 \%$ & 0.0006 & $73.2 \%$ & $68.9 \%$ & $77.8 \%$ & 0.0004 \\
\hline Small intestine & $91.6 \%$ & $90.3 \%$ & $93.4 \%$ & 0.0081 & $70.5 \%$ & $65.9 \%$ & $76.9 \%$ & 0.0103 \\
\hline Colon/rectum & $86.4 \%$ & $91.1 \%$ & $81.4 \%$ & 0.8154 & $74.1 \%$ & $75.3 \%$ & $73.0 \%$ & 0.9534 \\
\hline Esophagus/others ${ }^{b}$ & $70.4 \%$ & $68.1 \%$ & $73.6 \%$ & 0.1976 & $46.9 \%$ & $37.7 \%$ & $58.7 \%$ & 0.1796 \\
\hline
\end{tabular}

${ }^{a}$ The $P$-value for gender difference was calculated by the Kaplan-Meier method.

${ }^{b}$ Others: retroperitoneum and unspecific sites.

GIST include the improved quality of cancer registration, the advancement of diagnostic technology/method, and the increased awareness of GISTs by physicians which could be partly attributed to the emergence of effective targeted therapeutic agent, imatinib. Previously,

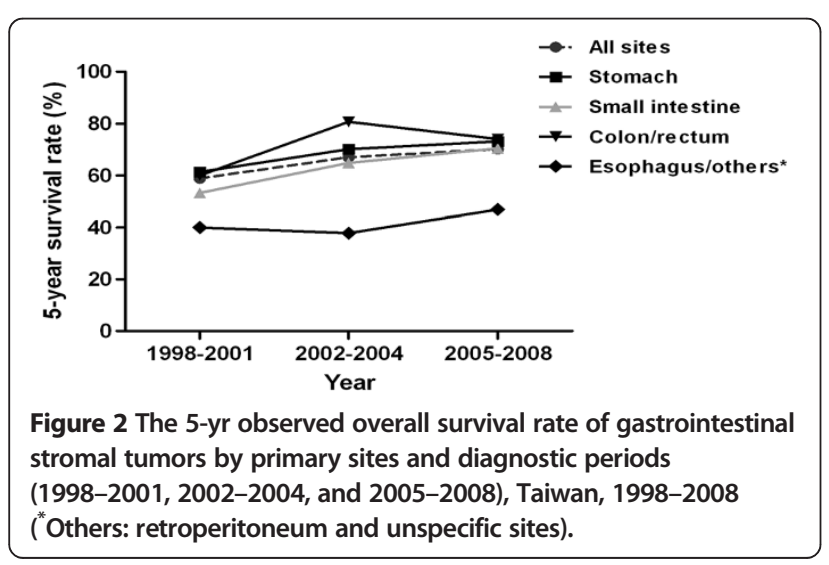

GISTs might have been misclassified as leiomyosarcoma, leiomyoma or unspecified sarcoma. The exact diagnosis and tumor origin of GISTs were difficult to determine until the discovery of the gain-of-function mutation in the KIT oncogene. In Taiwan, the routine use of CD117 or KIT immunohistochemical staining to diagnose GIST began in 2002. Before 2002, the diagnosis of GIST was based on histology with variable use of staining markers. In addition, no unique code indicating "gastrointestinal stromal sarcoma" was available in the ICD-O-FT, which was used by the TCR before 2002. The rising incidence of GISTs in Taiwan might be attributed to the increased utilization of CD117 staining and the increased awareness of GIST by the physicians. Nevertheless, there was still a rising trend of GIST incidence from 2005 to 2008, during which the use of CD117 or KIT immunohistochemical staining had already been widely adopted for the diagnosis of GISTs. Further follow-up is necessary to clarify whether the incidence of GISTs is truly on the 
Table 5 Survival analysis of patients with gastrointestinal stromal tumors, Taiwan, 1998-2008

\begin{tabular}{|c|c|c|c|c|c|c|}
\hline \multirow[b]{2}{*}{ Sex } & \multicolumn{3}{|c|}{ Univariable } & \multicolumn{3}{|c|}{ Multivariable } \\
\hline & $H^{a}$ & $95 \% \mathrm{Cl}^{\mathrm{a}}$ & $P$ & $H^{a}$ & $95 \% \mathrm{Cl}^{\mathrm{a}}$ & $P$ \\
\hline Male & Referent & & & Referent & & \\
\hline Female & 0.61 & $0.54-0.69$ & $<.0001$ & 0.68 & $0.60-0.77$ & $<.0001$ \\
\hline \multicolumn{7}{|l|}{ Age, years } \\
\hline$<50$ & Referent & & & Referent & & \\
\hline 50 to $<60$ & 1.23 & $1.00-1.52$ & 0.053 & 1.40 & $1.14-1.73$ & $<.0001$ \\
\hline 60 to $<70$ & 1.51 & $1.24-1.83$ & $<.0001$ & 1.74 & $1.44-2.12$ & $<.0001$ \\
\hline 70 to $<80$ & 2.73 & $2.27-3.27$ & $<.0001$ & 3.08 & $2.56-3.71$ & $<.0001$ \\
\hline$>80$ & 4.58 & $3.64-5.75$ & $<.0001$ & 5.69 & $4.51-7.17$ & $<.0001$ \\
\hline \multicolumn{7}{|l|}{ Primary site } \\
\hline Stomach & Referent & & & Referent & & \\
\hline Small intestine & 1.27 & $1.11-1.44$ & 0.0003 & 1.35 & $1.18-1.54$ & $<.0001$ \\
\hline Colon/rectum & 1.05 & $0.82-1.34$ & 0.6954 & 1.08 & $0.85-1.38$ & 0.5164 \\
\hline Esophagus/others ${ }^{\mathrm{b}}$ & 2.65 & $2.14-3.27$ & $<.0001$ & 2.51 & $2.01-3.12$ & $<.0001$ \\
\hline \multicolumn{7}{|l|}{ Year of diagnosis } \\
\hline 2005-2008 & Referent & & & Referent & & \\
\hline 1998-2001 & 1.42 & $1.21-1.65$ & $<.0001$ & 1.67 & $1.42-1.97$ & $<.0001$ \\
\hline 2002-2004 & 1.23 & $1.06-1.43$ & 0.0056 & 1.25 & $1.08-1.46$ & 0.0035 \\
\hline
\end{tabular}

${ }^{a}$ Hazard ratio $(\mathrm{HR})$ and $95 \%$ confidence interval $(\mathrm{Cl})$ were calculated based on Cox proportional hazards model.

${ }^{b}$ Others: retroperitoneum and unspecific sites.

rise. In addition, there was a disproportional rise in the incidence of GIST arising from esophagus/others compared to those from colon/rectum, especially during the 2002-2008 period. (Table 3 and Figure 1B). The increase in the incidence of GIST from esophagus/others resulted mostly from the elevated incidence of GIST located in retroperitoneum and unspecific sites (separate data not shown). The increased awareness of physicians with a more active approach to tumors arising from non-gastrointestinal sites due to the progress in the diagnostic tools and the availability of targeted therapy may partially account for this finding.

In our study, there was a slight male predominance $(\mathrm{M} / \mathrm{F}$ ratio $=1.0 \sim 1.3)$ in the incidence of GISTs, which was also observed by studies from Korea $(\mathrm{M} / \mathrm{F}$ ratio $=1.1)$ [19], Norway $(M / F$ ratio $=1.6)$ [22], and the United States $(\mathrm{M} / \mathrm{F}$ ratio $=1.46)[17]$. However, other studies reported a female excess in the number of GISTs [23-26], while one study reported no difference by sex [20]. Taken together, it is not clear whether there is a sex difference in the incidence of GIST, and if existed, may be insignificant. The age distribution of GIST patients in our study is consistent with those reported in the literature, with the majority of GIST patients being diagnosed during the fifth to the seventh decade of life. GISTs are occasionally found in young adults, but rarely among those younger than 18 years of age. In our series, stomach was the most frequent site of involvement (47-59\%) followed by small intestine (31-38\%) and colon/rectum (6-9\%). The site distribution of GISTs in our study is consistent with those published in the previous literature (stomach: $50-64 \%$, small intestine: $17-44 \%$, and colon/rectum: $2-19 \%$ ) [17,19-26]. In our study, the percentage of GISTs originated from stomach increased with age, while the percentage of GISTs originated in the small intestine decreased with age. To our knowledge, our study is the first to report this interesting finding, which could partially be explained by the more aggressive clinical behavior of small intestine GIST [27]. The more aggressive clinical course and thus the earlier signs and symptoms of GIST from the small intestine as opposed to the more indolent behavior of GIST from other sites may lead to the diagnosis of small intestine GIST at a younger age. However, more investigations are needed to determine the causes for the differences in the percentages of GIST location with increasing age.

Surgery remains the optimal therapy for the curative treatment of GISTs, but unfortunately, more than $50 \%$ of patients will develop recurrence or metastasis. Single or combined cytotoxic chemotherapy have failed to yield a satisfactory response. Prior to the introduction of tyrosine kinase inhibitors, the outcome for patients with metastatic disease was poor with a median survival of $<2$ years [28]. The prognosis of GIST improved dramatically after the introduction of imatinib, a tyrosine kinase inhibitor approved by the FDA in 2002 for treating KIT-positive GIST [29]. In Taiwan, imatinib became widely prescribed for 
recurrent or metastatic GISTs, after the approved coverage by the National Health Insurance Administration in 2004. In our analysis by the three time periods, the 5 -yr observed OS rate of GISTs improved with the introduction of imatinib as a GIST treatment (1998-2001: 59\% vs. 2002-2004: $67 \%$ ), and further improved with the approved coverage of imatinib by the National Health Insurance Administration (as a proxy for a wider usage) (2005-2008: 70\%). This is consistent with previous literature, with GISTs diagnosed in the pre-imatinib era having a 5-year survival ranging from $45 \%$ to $63 \%[4,17,21,22]$ and GISTs occurring in the imatinib era having a better 5 -year survival (79\%) [30].

In our analysis, besides the year of diagnosis, female sex, younger age, and stomach location were independent favorable prognostic factors of survival. The impact of the anatomic sites of GIST on survival is equivocal in the literature. In some studies, GIST arising from the stomach was less aggressive than those from other sites while other studies showed no difference [10,31,32]. Our study showed that GIST arising from the stomach had a better survival rate than those affecting the small intestine. Notably, GIST from the colon/rectum exhibited the best 5-yr observed OS of $72.4 \%$, although this survival advantage over GIST in the small intestine disappeared in the multivariable analysis, after adjusting for sex, age, and the year of diagnosis. The difference in survival between GISTs in the stomach and GISTs in the small intestine decreased with time $(6.1 \%$ in $1998-2001 ; 5.2 \%$ in $2002-2004 ; 2.7 \%$ in 2005-2008), which could be attributed to the advancement in treatment, such as the use of imatinib. In our multivariable analysis, female sex was an independent favorable prognostic factor for survival (Table 5). The magnitude of survival advantage of women over men persisted (Additional file 1: Table S1, S2, S3) even during the era of imatinib treatment. Using SEER data, Tran et al. observed a survival advantage of women over men (women vs. men: 5-yr mortality risk HR $=0.83,95 \%$ CI: 0.71-0.97) [17]. Similarly, in another cancer registry-based study of $46 \mathrm{c}-\mathrm{KIT}$ confirmed cases diagnosed in 1994-2001, women had a better 5 -year survival than men (75\% vs. $52 \%$ ) [21]. In a cohort of 1,215 GISTs patients diagnosed between May, 2000 and October 2010, Call et al. also reported a better GIST survival in women compared to men (men vs. women: $\mathrm{HR}=1.5,95 \% \mathrm{CI}: 1.2-1.8$ ) [30]. It is unclear what contributes to the better survival of GISTs among women compared to men and further investigations are warranted.

This study has several strengths. This is the first nation-wide cancer registry-based study of GIST and one of the largest GIST studies from Asia. Because the GIST cases were identified from a nation-wide cancer registry, our results are population-based with a reduced probability of selection bias associated with identifying GISTs from a single or a few medical institutions. The other major strength is the long study period from 1998-2008, which spanned across the eras of pre-imatinib, transition, and imatinib, and allowed us to demonstrate the influence of change in treatment practice on the survival of GIST patients.

This study has several limitations. The TCR does not have complete information on the tumor size of GISTs and lacks data on mitotic index; therefore, risk stratification according to the Armed Forces Institute of Pathology (AFIP) criteria (also known as Miettinen's criteria) to predict the prognosis of GISTs was not possible [33]. We used multiple ICD-O codes to represent GIST diagnosed in 1998-2001 due to the lack of an ICD-O code specific for GIST and the absence of confirmation by c-KIT staining. As a result, the incidence rates for 1998-2001 might have been overestimated due to the potential inclusion of other non-GIST mesenchymal tumors. However, studies suggested that that the majority of gastrointestinal tumors previously classified as tumors of smooth muscle, including leiomyosarcoma or nerve sheath tumors were GISTs [2,34], which is consistent with our GISTs cases identified for the 19982001 period (83.5\% was leiomyosarcoma, followed by $8.85 \%$ of sarcoma, not otherwise specified, and $3.36 \%$ of epithelioid leiomyosarcoma). In addition, compared to GISTs diagnosed during 2002-2008 after the establishment of c-KIT staining as part of the diagnostic protocol and identified by a single ICD-O-3 code (8936: gastrointestinal stromal sarcoma), GISTs from 1998-2001 showed similar distributions of sex, age, and primary sites (Table 1), supporting that the majority of our cases from 1998-2001 were likely GIST. Finally, although our analysis suggested that the introduction and the wider use of imatinib could contribute to the improved survival of GIST patients, it is possible that other factors may have enhanced the survival of GIST patients, including increased awareness of the disease, earlier diagnosis, improved treatment, and better overall population health.

\section{Conclusions}

The incidence of GISTs in Taiwan is comparable to those reported by the US and European studies. GIST is a rare cancer in Taiwan and its incidence has been increasing gradually, partially due to the advancement of diagnostic technology/method and the increased awareness of GISTs by physicians. The occurrence of GISTs is more common in men and the older population. The stomach is the most common primary site followed by the small intestine. Prognostic factors for a better survival of GIST include female sex, younger age, stomach location, and diagnostic years (likely as a proxy for change in treatment practice). Finally, our results suggest that the survival of patients with GIST has improved significantly by targeted therapy. 


\section{Additional file}

Additional file 1: Table S1. Survival analysis of patients with gastrointestinal stromal tumors, Taiwan, 1998-2001. Table S2. Survival analysis of patients with gastrointestinal stromal tumors, Taiwan, 2002-2004. Table S3. Survival analysis of patients with gastrointestinal stromal tumors, Taiwan, 2005-2008.

\section{Competing interests}

The authors declare no conflicts of interest.

\section{Authors' contributions}

All authors designed the study. CRT and JSC performed statistical analyses. All authors interpreted the results. NJC and JSC drafted the manuscript. All authors read and approved the final manuscript.

\section{Acknowledgements}

The current analysis was based on data provided by the Collaboration Center of Health Information Application (CCHIA), Department of Health, Executive Yuan, Taiwan. This work was supported by the Establishment of Cancer Research System Excellence Program, Department of Health, Executive Yuan, Taiwan (Grant number: DOH-102-TD-C-111-004; CA-103-SP-01).

\section{Author details}

${ }^{1}$ National Institute of Cancer Research, National Health Research Institutes, 2 F, No. 367, Sheng Li Road, Tainan 70456, Taiwan. 'Division of Hematology/ Oncology, Department of Internal Medicine, National Cheng Kung University Hospital, 138 Sheng Li Road, Tainan 70456, Taiwan. ${ }^{3}$ Department of Internal Medicine, Kaohsiung Medical University Hospital, Kaohsiung Medical University, No. 100, Ziyou 1st. Road, Sanmin District, Kaohsiung 807, Taiwan. ${ }^{4}$ School of Pharmacy, College of Pharmacy, Taipei Medical University, 250 Wu-Hsing Street, Taipei 110, Taiwan.

Received: 23 July 2013 Accepted: 12 February 2014 Published: 18 February 2014

\section{References}

1. Kitamura Y, Hirota S, Nishida T: Gastrointestinal stromal tumors (GIST): a model for molecule-based diagnosis and treatment of solid tumors. Cancer Sci 2003, 94(4):315-320.

2. Fletcher CD, Berman JJ, Corless C, Gorstein F, Lasota J, Longley BJ, Miettinen M, O'Leary TJ, Remotti H, Rubin BP, et al: Diagnosis of gastrointestinal stromal tumors: a consensus approach. Hum Pathol 2002, 33(5):459-465.

3. Mazur MT, Clark HB: Gastric stromal tumors. Reappraisal of histogenesis. Am J Surg Pathol 1983, 7(6):507-519.

4. Chan KH, Chan CW, Chow WH, Kwan WK, Kong CK, Mak KF, Leung MY, Lau LK: Gastrointestinal stromal tumors in a cohort of Chinese patients in Hong Kong. World J Gastroenterol 2006, 12(14):2223-2228.

5. Wang X, Mori I, Tang W, Utsunomiya H, Nakamura M, Nakamura Y, Zhou G, Kakudo K: Gastrointestinal stromal tumors: clinicopathological study of Chinese cases. Pathol Int 2001, 51(9):701-706.

6. Corless CL, McGreevey L, Haley A, Town A, Heinrich MC: KIT mutations are common in incidental gastrointestinal stromal tumors one centimeter or less in size. Am J Pathol 2002, 160(5):1567-1572.

7. Miettinen M, Lasota J: Gastrointestinal stromal tumors-definition, clinical histological, immunohistochemical, and molecular genetic features and differential diagnosis. Virchows Arch 2001, 438(1):1-12.

8. Hirota S, Isozaki K, Moriyama Y, Hashimoto K, Nishida T, Ishiguro S, Kawano K, Hanada M, Kurata A, Takeda M, et al: Gain-of-function mutations of c-kit in human gastrointestinal stromal tumors. Science (New York, NY) 1998 279(5350):577-580.

9. Li CF, Chuang SS, Lu CL, Lin CN: Gastrointestinal stromal tumor (GIST) in southern Taiwan: a clinicopathologic study of 93 resected cases. Pathol Res Pract 2005, 201(1):1-9.

10. DeMatteo RP, Lewis JJ, Leung D, Mudan SS, Woodruff JM, Brennan MF: Two hundred gastrointestinal stromal tumors: recurrence patterns and prognostic factors for survival. Ann Surg 2000, 231(1):51-58.

11. Hassan I, You YN, Shyyan R, Dozois EJ, Smyrk TC, Okuno SH, Schleck CD, Hodge DO, Donohue $\mathrm{JH}$ : Surgically managed gastrointestinal stromal tumors: a comparative and prognostic analysis. Ann Surg Oncol 2008, 15(1):52-59.

12. Dagher R, Cohen M, Williams G, Rothmann M, Gobburu J, Robbie G, Rahman A, Chen G, Staten A, Griebel D, et al: Approval summary: imatinib mesylate in the treatment of metastatic and/or unresectable malignant gastrointestinal stromal tumors. Clin Cancer Res 2002, 8(10):3034-3038.

13. Bureau of Health Promotion, Department of Health, the Executive Yuan, Taiwan: Cancer Registry Annual Report, Taiwan. Available on http://www. hpa.gov.tw Accessed on April 16, 2013.

14. Bray F, Parkin DM: Evaluation of data quality in the cancer registry: principles and methods. Part I: comparability, validity and timeliness. Eur J Cancer 2009, 45(5):747-755.

15. Shin HR: [Global activity of cancer registries and cancer control and cancer incidence statistics in Korea]. J Prev Med Public Health 2008, 41(2):84-91.

16. Larsen IK, Smastuen M, Johannesen TB, Langmark F, Parkin DM, Bray F, Moller B: Data quality at the cancer registry of Norway: an overview of comparability, completeness, validity and timeliness. Eur J Cancer 2009, 45(7):1218-1231

17. Tran T, Davila JA, El-Serag HB: The epidemiology of malignant gastrointestinal stromal tumors: an analysis of 1,458 cases from 1992 to 2000. Am J Gastroenterol 2005, 100(1):162-168.

18. Tzen CY, Wang JH, Huang YJ, Wang MN, Lin PC, Lai GL, Wu CY: Incidence of gastrointestinal stromal tumor: a retrospective study based on immunohistochemical and mutational analyses. Dig Dis Sci 2007, 52(3):792-797.

19. Cho MY, Sohn JH, Kim JM, Kim KM, Park YS, Kim WH, Jung JS, Jung ES, Jin SY, Kang DY, et al: Current trends in the epidemiological and pathological characteristics of gastrointestinal stromal tumors in Korea, 2003-2004. J Korean Med Sci 2010, 25(6):853-862.

20. Nilsson B, Bumming P, Meis-Kindblom JM, Oden A, Dortok A, Gustavsson B, Sablinska K, Kindblom LG: Gastrointestinal stromal tumors: the incidence, prevalence, clinical course, and prognostication in the preimatinib mesylate era-a population-based study in western Sweden. Cancer 2005, 103(4):821-829.

21. Rubio J, Marcos-Gragera R, Ortiz MR, Miro J, Vilardell L, Girones J, Hernandez-Yague X, Codina-Cazador A, Bernado L, Izquierdo A, et al: Population-based incidence and survival of gastrointestinal stromal tumours (GIST) in Girona, Spain. Eur J Cancer 2007, 43(1):144-148.

22. Steigen SE, Eide TJ: Trends in incidence and survival of mesenchymal neoplasm of the digestive tract within a defined population of northern Norway. Apmis 2006, 114(3):192-200.

23. Mucciarini C, Rossi G, Bertolini F, Valli R, Cirilli C, Rashid I, Marcheselli L, Luppi G, Federico M: Incidence and clinicopathologic features of gastrointestinal stromal tumors. A population-based study. BMC Cancer 2007, 7:230.

24. Monges G, Bisot-Locard S, Blay JY, Bouvier AM, Urbieta M, Coindre JM, Scoazec JY: The estimated incidence of gastrointestinal stromal tumors in France. Results of PROGIST study conducted among pathologists. Bull Cancer 2010, 97(3):E16-E22

25. Yan BM, Kaplan GG, Urbanski S, Nash CL, Beck PL: Epidemiology of gastrointestinal stromal tumors in a defined Canadian Health Region: a population-based study. Int J Surg Pathol 2008, 16(3):241-250.

26. Ahmed I, Welch NT, Parsons SL: Gastrointestinal stromal tumours (GIST) 17 years experience from Mid Trent Region (United Kingdom). Eur J Surg Oncol 2008, 34(4):445-449.

27. Miettinen M, Lasota J: Gastrointestinal stromal tumors: review on morphology, molecular pathology, prognosis, and differential diagnosis. Arch Pathol Lab Med 2006, 130(10):1466-1478.

28. Dematteo RP, Heinrich MC, El-Rifai WM, Demetri G: Clinical management of gastrointestinal stromal tumors: before and after STI-571. Hum Pathol 2002, 33(5):466-477.

29. Demetri GD, von Mehren $M$, Blanke CD, Van den Abbeele AD, Eisenberg $B$, Roberts PJ, Heinrich MC, Tuveson DA, Singer S, Janicek M, et al: Efficacy and safety of imatinib mesylate in advanced gastrointestinal stromal tumors. N Engl J Med 2002, 347(7):472-480.

30. Call J, Walentas CD, Eickhoff JC, Scherzer N: Survival of gastrointestinal stromal tumor patients in the imatinib era: life raft group observational registry. BMC Cancer 2012, 12:90.

31. Emory TS, Sobin LH, Lukes L, Lee DH, O'Leary TJ: Prognosis of gastrointestinal smooth-muscle (stromal) tumors: dependence on anatomic site. Am J Surg Pathol 1999, 23(1):82-87. 
32. Yan $\mathrm{H}$, Marchettini $\mathrm{P}$, Acherman $\mathrm{Yl}$, Gething $\mathrm{SA}$, Brun $\mathrm{E}$, Sugarbaker $\mathrm{PH}$ : Prognostic assessment of gastrointestinal stromal tumor. Am J Clin Oncol 2003, 26(3):221-228.

33. Miettinen M, Lasota J: Gastrointestinal stromal tumors: pathology and prognosis at different sites. Semin Diagn Pathol 2006, 23(2):70-83.

34. Berman J, O'Leary TJ: Gastrointestinal stromal tumor workshop. Hum Pathol 2001, 32(6):578-582.

doi:10.1186/1471-2407-14-102

Cite this article as: Chiang et al:: The epidemiology of gastrointestinal stromal tumors in Taiwan, 1998-2008: a nation-wide cancer registrybased study. BMC Cancer 2014 14:102.

\section{Submit your next manuscript to BioMed Central and take full advantage of:}

- Convenient online submission

- Thorough peer review

- No space constraints or color figure charges

- Immediate publication on acceptance

- Inclusion in PubMed, CAS, Scopus and Google Scholar

- Research which is freely available for redistribution 